\section{Sudden cardiac death during open water swimming}

\author{
Michael J Tipton
}

Since becoming an Olympic event in 2008, open water swimming has become one of the fastest growing mass participation sports worldwide; events have taken place with over 25000 participants. With these numbers comes an inherent risk of adverse medical events. The recently released USA Triathlon (USAT) Fatality Incidents Study ${ }^{1}$ reviewed data from 2003 to 2011 and reports that over that period 43 athlete fatalities were recorded during race events. Of these, five were considered 'traumatic', caused during cycling; of the remaining 38 deaths, 30 occurred during the swim.

These data suggest that a swim represents the greatest relative hazard associated with mass participation sports events. Despite this, the mechanism and cause of death remains something of a mystery; in the USAT Fatality Incidents Study, autopsy information was not reviewed, but it is concluded that 'available data indicates the swimming fatalities appear to be caused by episodes of sudden cardiac death (SCD)'having not found enough evidence of deaths caused by swimming-induced pulmonary edema (SIPE) - a popular theory of cause of death in the media and specific triathlon forums. There was also no clear evidence that swimming ability, anxiety, wet suit-related factors or medical problems such as stroke, seizure or syncope were responsible for the deaths during swimming. Furthermore, from other media reports, those that die are often regarded as being fit and healthy.

From the USAT study, swim death rates do not appear to have been influenced by the length of the race, method of swim start (mass, wave or time trial start), course conditions, organisation or previous triathlon experience. No information is given about when in the swims the problems occurred, for example, when swimmers were isolated or swimming closely with others; this information may have

Extreme Environments Laboratory, Department of Sport and Exercise Science, University of Portsmouth,

Portsmouth, UK

Correspondence to Michael J Tipton, Extreme Environments Laboratory, Department of Sport and Exercise Science, University of Portsmouth, Cambridge Road, Portsmouth P01 2ER, UK;

michael.tipton@port.ac.uk been revealing. The vast majority of the victims were rescued from the water and received cardiopulmonary resuscitation (CPR) and advanced life support measures at the scene.

It is noteworthy that all of the deaths occurred in open water as opposed to indoor swimming pools; however, it is a reasonable assumption that many of those that died during the swim will have trained in open water with similar temperatures and conditions, possibly excluding environmental factors as a contributory cause ${ }^{2}$ and raising the intriguing question of what it is about in a mass participation competitive event per se that is significant with regard to SCD? Kim et $a l^{3}$ report that many episodes of SCD during long distance running are thought to be due to an underlying, often unrecognised, abnormal heart condition such as coronary artery disease or hypertrophic cardiomyopathy. Previous autopsy findings in triathlon victims have shown cardiac abnormalities (eg, mild left ventricular hypertrophy or coronary artery anomalies) with no other explanatory cause for death. ${ }^{1}$ However, such pathology will be present during training as well as actual events. We have recently proposed a possible mechanism of SCD on immersion and other situations ${ }^{4}$ : 'Autonomic Conflict' (AC) occurs when both divisions of the autonomic nervous system are co-activated resulting in cardiac arrhythmias and, possibly, death. In the circumstance of an open water competitive

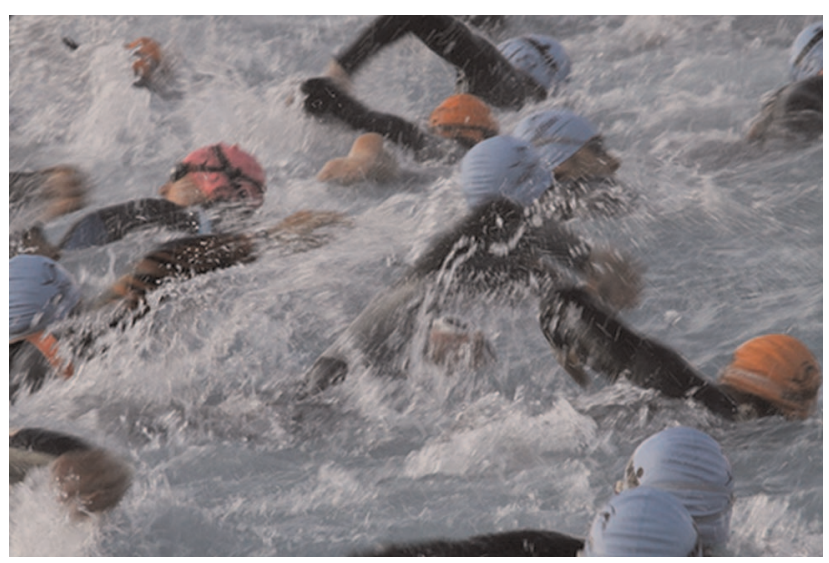

Figure 1 It seems possible that, during a competitive open water swimming race, circumstances could arise that would increase the likelihood of autonomic conflict, producing a fatal arrhythmia in some people. These circumstances are less likely during training. swim, sympathetic activation could occur due to water temperature and exercise (also experienced during training), anxiety, anger/overcompetitiveness (competitionspecific). Of all the emotions, anger is the one most associated with ventricular fibrillation; it increases the sympathetic tone while maintaining a parasympathetic tone. ${ }^{5}{ }^{6}$ Parasympathetic activation could occur simultaneously as a result of facial wetting (experienced in training), water entering the nasopharynx and extended breath holding (both more likely in the confused water of a mass swim, figure 1).

Therefore, it seems possible that during a competitive open water swim, circumstances could arise that would increase the likelihood of AC producing a fatal arrhythmia in some people (figure 1). These circumstances (anger, competition, water entering the nasopharynx, extended breath holding) would not normally be present during open water swim training. Being an electric disturbance of the heart, it is not possible to detect AC postmortem, and other pathology is usually sought (eg, 'dry drowning') or erroneously identified (eg, drowning) when undetectable cardiac problems result in the aspiration of water. ${ }^{4}$

It is worth noting that even with good treatment for sudden cardiac arrest (prompt bystander CPR; early defibrillation and follow-up hospital care), the survival rate for sports-related sudden cardiac arrest is $10-29 \% .^{13}$ Thus, in comparison with the best that is currently available, there would seem to be little scope at present for preventing SCD in open water swimming events in terms of improved screening, organisation or rescue and resuscitation protocols. Hopefully, future research will help identify more precisely those that are at risk, and why. 


\section{Competing interests None.}

Provenance and peer review Not commissioned; internally peer reviewed.

To cite Tipton MJ. Br J Sports Med Published Online First: [please include Day Month Year] doi:10.1136/ bjsports-2012-092021

Received 22 November 2012

Revised 22 November 2012

Accepted 1 January 2013

Br J Sports Med 2013;0:1-2.

doi:10.1136/bjsports-2012-092021

\section{REFERENCES}

1 USA Triathlon (USAT). http://www.usatriathlon.org/ news/articles/2012/10/102512-medical-panel-report. aspx (Accessed Nov 2012).

2 Tipton MJ, Franks CM, Gennser M, et al. Immersion death and deterioration in swimming performance in cold water. Lancet 1999;354:626-9.

$3 \mathrm{Kim} \mathrm{JH}$, Malhotra R, Chiampas G, et al. Cardiac arrest during long-distance running races. New Engl J Med 2012;366:130-40.
4 Shattock M, Tipton MJ. 'Autonomic conflict': a different way to die on immersion in cold water? J Physiol 2012;590:3219-30.

5 Lampert R, Joska T, Burg MM, et al. Emotional and physical precipitants of ventricular arrhythmia. Circulation 2002;106:1800-5.

6 Rainville P, Bechara A, Naqvi N, et al. Basic emotions are associated with distinct patterns of cardiorespiratory activity. Int J Psychophysiol 2006;61:5-18. 


\section{BJSM}

\section{Sudden cardiac death during open water swimming}

Michael J Tipton

Br J Sports Med published online February 1, 2013

doi: 10.1136/bjsports-2012-092021

Updated information and services can be found at:

http://bjsm.bmj.com/content/early/2013/01/31/bjsports-2012-092021.full.html

\section{These include:}

References This article cites 5 articles, 2 of which can be accessed free at: http://bjsm.bmj.com/content/early/2013/01/31/bjsports-2012-092021.full.html\#ref-list-1

$\mathbf{P}<\mathbf{P} \quad$ Published online February 1, 2013 in advance of the print journal.

Email alerting

Receive free email alerts when new articles cite this article. Sign up in the box at the top right corner of the online article.

Notes

Advance online articles have been peer reviewed, accepted for publication, edited and typeset, but have not not yet appeared in the paper journal. Advance online articles are citable and establish publication priority; they are indexed by PubMed from initial publication. Citations to Advance online articles must include the digital object identifier (DOIs) and date of initial publication.

To request permissions go to:

http://group.bmj.com/group/rights-licensing/permissions

To order reprints go to:

http://journals.bmj.com/cgi/reprintform

To subscribe to BMJ go to:

http://group.bmj.com/subscribe/ 